RESEARCH ARTICLE

\title{
Women Using a Web-based Digital Health Coaching Programme for Stress Management: Stress Sources, Symptoms and Coping Strategies
}

\author{
Danielle L. Giuseffi ${ }^{1}$, Richard C. Bedrosian ${ }^{1,2}$, Steven M. Schwartz ${ }^{1,3 * \dagger}$, Kevin J. Wildenhaus ${ }^{1}$, \\ Chun Wang ${ }^{1}$, Alvin $\mathrm{Yu}^{1}$ \& Ben Wiegand ${ }^{4}$ \\ ${ }^{1}$ HealthMedia, Inc., Ann Arbor, MI, USA \\ ${ }^{2}$ University of Massachusetts Medical School, Worcester, MA, USA \\ ${ }^{3}$ Department of Psychiatry, University of Michigan, Ann Arbor, MI, USA \\ ${ }^{4}$ Johnson \& Johnson, New Brunswick, NJ, USA
}

\begin{abstract}
Researchers have proposed and tested many theories to understand gender differences in stress experiences. However, little research has identified differences between subgroups of women in terms of stress sources, symptoms, coping strategies and help-seeking behaviour. The purpose of this study was to examine these characteristics of women seeking help for stress management through a digital health coaching programme. We examined cross-sectional data from 63,690 women between the ages of 18 and 59 years who participated in the stress management programme from 2001 to 2008 . We divided the sample into age groups to identify developmental patterns in their stress characteristics.

Work, time demands and psychological reactions to stress were consistent concerns, whereas between-group comparisons indicated diverse stress characteristics by age group. Importantly, women at all ages reported being uncomfortable asking for help. The findings suggest that technology-based solutions like digital health coaching may reach women who may not otherwise seek or receive help for stress management. The results also emphasize the importance of considering the unique characteristics of women when providing them stress management interventions. Copyright (c) 2011 John Wiley \& Sons, Ltd.
\end{abstract}

Received 22 February 2010; Revised 17 December 2010; Accepted 21 December 2010

Keywords

life stress; women; coping strategies; emotions; technology

${ }^{*}$ Correspondence

Steven M. Schwartz, HealthMedia, Inc. 130 South 1st Street Ann Arbor, MI 48104, USA.

†Email: sschwartz@healthmedia.com

Published online 8 March 2011 in Wiley Online Library (wileyonlinelibrary.com) DOI: 10.1002/smi.1389

\section{Introduction}

Stress was originally defined by Selye (1976) as the non-specific response of the body to any demand. In current usage, the term typically refers to both physiological and psychological responses to increased demands on the organism. Stress is a high-prevalence global problem. A 2006 international poll showed that nearly $75 \%$ of residents of developed countries reported feeling stressed on a daily basis (Associated Press-Ipsos, 2006). The Stress in America survey assessed attitudes and perceptions of stress among 1848 US adults. Over half of respondents (52\%) were concerned about their current stress level, whereas one in three reported experiencing an extreme degree of stress (APA, 2009).
Although the exact psychobiological mechanisms remain elusive, stress is linked to many common, costly health conditions, including cardiovascular disease (Hamer, Molloy, \& Stamatakis, 2008), obesity (Laitinen, Ek, \& Sovio, 2002), asthma (Priftis \& Anthracopoulos, 2008), headaches (Martin, Lae, \& Reece, 2007), migraines (Mathews, Stubits, \& Nigam, 1982), irritable bowel syndrome (Locke, Weaver, Melton, \& Talley, 2004), lupus, rheumatoid arthritis (Jacobs et al., 2001) and diabetes (Shiloah \& Rapoport, 2006). Many exacerbate difficulties with stress by engaging in unhealthy coping behaviours such as smoking, alcohol/drug use and over/undereating (APA, 2009; Steptoe, Lipsey, \& Wardle, 1998). These behaviours themselves are well-supported risk factors for disease and compromised well-being (Parrott, 
1995; Pohorecky, 1991; Smith, 2002; Thadani, 2002). The Foundation for Integrated Research in Mental Health (2007) estimated that more than three-fifths of doctor visits worldwide are from stress-related issues.

Women report higher levels of daily and chronic stress compared with men (Matud, 2004). Women's sources of stress differ from male counterparts. Women are more likely to report home and family life events (Oman \& King, 2000) and caregiving roles as stressful (Lee, 2001). Women in the United States report higher rates of negative emotional reactions (e.g. irritability, sadness) and physical symptoms (e.g. headache, gastrointestinal complaints) in response to stress (APA, 2009). Further, women are more likely to use prescription medications and over/undereat to cope with stress (APA, 2007, 2009).

Researchers have proposed many theories to explain gender differences in stress experiences (Kessler \& McLeod, 1984; Ptacek, Smith, \& Zanas, 1992; Rosario, Shinn, Morch, \& Huckabee, 1988). Although gender comparisons have value, they tend to gloss over the variability in women's stress experiences. There is increasing interest among researchers in differences between subgroups of women in terms of sources of stress, stress symptoms, coping strategies and helpseeking behaviour (Banyard \& Graham-Bermann, 1993; Kayser, Sormanti, \& Strainchamps, 1999). Rather than examining how women differ from men in their stress experiences, the intent of this paper was to better describe the demographic, psychological and symptomatic characteristics of women experiencing stress.

One way to explore women's unique stress characteristics is to look at stress differences across the lifespan. For example, stressors facing young adults are different from older adults. A 2007 study assessed types of stressors across the lifespan (Amirkhan \& Auyeung, 2007). Young adults rated jobs/money (33\%), school $(23 \%)$ and family $(18 \%)$ as their top stressors, whereas older adults rated jobs/money (39\%), family (35\%) and health $(7 \%)$ as their top stressors. Only $2 \%$ of young adults reported health as a stressor (Amirkhan \& Auyeung, 2007). Overall, researchers found that adults in their 20s reported more perceived stress than those in their 50s (Stone, Schwartz, Broderick, \& Deaton, 2010). Young adults also reported greater psychological distress including anger and physical symptoms in response to stress (Neupert, Almeida, \& Charles, 2007).

The ability to self-regulate emotion when dealing with stress increases with age (Compas, 1998). Although different types of coping strategies-problem solving, distraction, avoidance, blame, acceptance and social support-are employed throughout the lifespan, the extent to which they are utilized varies. As age increases, problem-solving coping strategies increase, and avoidance coping strategies decrease (Amirkhan \& Auyeung, 2007). Social support can be an effective buffer against stress as well as a resource to turn to for help with coping with stress (Cohen, Gottlieb, \&
Underwood, 2000; Cohen \& Wills, 1985). Actual or perceived social support has been linked to positive health outcomes in diverse populations across all age groups (Cohen \& Wills, 1985; Ozbay, Fitterling, Charney, \& Southwick, 2008).

Despite the high prevalence and impact of stress problems across the lifespan, relatively few people seek professional help. Although $69 \%$ of US adults agreed that a mental health professional could enhance stress management, only $7 \%$ sought professional help (APA, 2007). Research indicates that factors such as situational barriers (e.g. unsure where to go to get help, inconvenient), financial barriers, perceived lack of effectiveness and the desire to solve problems on one's own hold back many with mental health problems from seeking treatment (Kessler et al., 2001). In a survey of UK adults, $81 \%$ of respondents said they would seek help only if their physical health were really suffering as a result of stress (Oliver, Pearson, Coe, \& Gunnell, 2005). Young adults appear to be particularly affected by the stigma associated with mental illness (Crisp \& Rickwood, 2006; Donald, Dower, Lucke, \& Rachael, 2000).

Little research has focused on the characteristics of women seeking help for stress management, including demographics, attitudes, symptoms and coping strategies. This study examines the characteristics of women aged 18 to 59 years who participated in a web-based intervention called digital health coaching. The term 'digital health coaching' is increasingly being used to identify technology-based, automated interventions to differentiate them from multimedia psycho-educational programmes or generic healthrelated information delivered electronically (Strecher, 2009). Because digital health coaching can generate high participation rates and routinely collects data, it provides an opportunity to study a large sample of women seeking help for stress, thereby identifying the specific needs and concerns of this population.

We hypothesized that within a sample of female participants in digital health coaching programme for stress management (1) the sources of stress would vary by age, reflecting the corresponding developmental challenges; (2) older women would experience less psychological distress related to stress than their younger counterparts; and (3) there would be differences in coping strategies between age groups, reflecting the more extensive life experiences of older women. Lastly, we also sought to determine how the help-seeking sample compared with women who reported experiencing stress but did not participate in the stress management intervention.

\section{Materials and methods}

\section{Participants}

This study analysed the responses of 63,690 women who enrolled in a digital health coaching programme 
for stress management between 2001 and 2008. Their ages ranged from 18 to 59 years. Participants were geographically dispersed throughout the United States.

\section{Inclusion criteria}

Participating employers and health insurance plans purchased digital health coaching programmes, including a health-risk appraisal (HRA) and the stress management programme, from a commercial vendor. The digital coaching programmes were offered to employees or health insurance plan members as part of their health benefit offerings. Participants in the study were either employees or their family members, or members of the health insurance plans in question.

\section{Study design}

This was a retrospective, descriptive study. The sample was divided into generational groups by decade (18-29, 30-39, 40-49 and 50-59) in order to identify variation in the participants' stress characteristics across the lifespan. Because the study was cross-sectional in nature, the age groups were not intended to make broad, generalized statements about the individuals' patterns of development.

Prospective participants were recruited by mailings, emails and posted communications about the digital coaching programmes. Invitations were sent by employers or health insurance plans to eligible participants. The invitation contained instructions on how to access the digital coaching programmes and provided access codes necessary for enrollment.

Employers and health insurance plans encouraged employees and members to complete an online HRA annually, as a health promotion strategy. The HRA was used to identify risk factors, including stress. During the study's time frame (2001 to 2008), 181,464 women aged 18 to 59 years reported in the HRA that they were fairly often or very often stressed during the past month. Of these high-risk women, $35.1 \%$ took the digital coaching programme for stress management. The high-risk women who did not participate in the stress management programme served as the non-participant comparison group for this study.

Prior to enrolling in the digital coaching programme, participants were instructed to read a statement of informed consent. The informed consent included permission to evaluate data in an aggregated, deidentified manner for research purposes. The participants opted in if they understood the details of participation, their level of involvement in the study and their rights as a participant. The informed consent and the study protocol were reviewed and approved by an independent institutional review board.

Participants in the stress management digital coaching programme completed the online baseline questionnaire, as described below.

\section{Materials}

\section{Online baseline questionnaire}

The programme architecture required that participants complete a baseline assessment before receiving the tailored digital coaching plan. The baseline assessment included 29 questions covering demographic, medical and psychographic information, as well as quality of life and health. The participants were asked about their sources of stress, how stress affected them physically, emotionally and interpersonally and their coping strategies (both healthy and unhealthy). The section below describes measures used to assess stress-related variables. The digital health coaching intervention was described in a prior publication (Wiegand, Luedtke, Mona Nair, Aleles, \& McCloskey, 2010).

\section{Stress levels}

The four-item validated version Perceived Stress Scale (PSS-4) (Cohen, Kamarck, \& Mermelstein, 1983) was embedded within the online assessment and was used to identify symptomatic stress levels. Three other questions from the PSS long form were added to the four-item version for descriptive purposes to identify the participants' emotional responses to stress and the degree to which they felt they could effectively deal with stress (Cohen et al., 1983). See Table I for PSS items used. The total PSS score was calculated from the PSS-4. The higher the total PSS score, the higher the stress level.

\section{Sources of stress}

Participants were asked about the major categories of stressors: daily work or activity, financial situation, home and family life, personal and social life and health (Rahe \& Tolles, 2002). The responses for each category were adopted from the 43 life stressful events in the Social Readjustment Rating Scale (SRRS) (Holmes \& Rahe, 1967). The SRRS validity extends to different populations within the United States (Komaroff, Masuda, \& Holmes, 1968) as well as crossculturally (Woon, Masuda, Wagner, \& Holmes, 1971).

Participants were asked to identify one primary source from the major categories of stressors. Situational stressors resulting from specific environments or circumstances were assessed by asking participants which situations (work or school responsibilities, family responsibilities or both) made it difficult to meet their life demands.

\section{Stress symptoms}

The Brief Stress and Coping Inventory (BSCI) is the short form of the Stress and Coping Inventory (SCI) (Rahe \& Tolles, 2002) and is used to identify stress symptoms and coping through 10 subscales (Rahe \& Tolles, 2002). Items from only three subscales (physical symptoms, psychological symptoms and behaviours and 
Table I. Items adopted from the Perceived Stress Scale (PSS) short and long forms

Item
In the last month, how often have you felt that you were unable to control the important things in your life?
In the last month, how often have you felt confident about your ability to handle your personal problems?
In the last month, how often have you felt that things were going your way?
In the last month, how often have you felt difficulties were piling up so high that you could not overcome them?
In the last month, how often have you felt nervous or stressed?
In the last month, how often have you been angered because of things outside of your control? $\quad$ English; four items
In the last month, how often have you felt that you were on top of things?

Note. The response to each item was a five-point Likert type scale: $0=$ never, $1=$ almost never, $2=$ sometimes, $3=$ fairly often, $4=$ very often.

${ }^{\dagger}$ Cohen et al., 1983.

emotions) were integrated into the online baseline questionnaire.

The participants were asked which stress symptoms they experienced: physical symptoms (e.g. headache, upset stomach), psychological symptoms (e.g. decreased concentration, excessive worry or anxiety) and behaviours and emotions (e.g. difficulty sleeping, lack enjoyment from usual activities). The participants were also asked to identify their greatest concern related to stress symptoms (physical symptoms, emotional reactions or changes in behaviour).

The three subscales used in this study (physical symptoms, psychological symptoms and behaviours and emotions) from the BSCI were validated against the correlating subscales (physical symptoms, psychological symptoms and behaviours and emotions) in the long SCI instrument (Rahe \& Tolles, 2002). Because not all items in the subscales were used, subscale scores were not calculated.

\section{Coping strategies}

The Coping Styles Questionnaire was employed to assess the participants' coping techniques (Davis, Eshelman, \& McKay, 2000). Effective coping also includes stress prevention techniques such as managing time effectively and scheduling planned relaxation activities. The perception of available social support is strongly correlated to the benefits of social support regardless of the actual level of support available (Barrera, 1986; Wetherington \& Kessler, 1986). Participants were asked to identify their perceived available social support in the baseline questionnaire by selecting statements that were true for them (e.g. I feel that I get enough support from my family or friends when I need help).

\section{Self-efficacy}

Bandura (1977) describes self-efficacy as an individual's belief that he or she is capable of engaging in a specific behaviour. Degree of self-efficacy has been found to predict whether individuals will continue to engage in positive coping strategies in the face of obstacles. Self-efficacy to manage stress was assessed by using two constructs: motivation to manage stress and confidence to manage stress.

\section{Web-based health-risk appraisal}

The HRA data were used to compare study participants with non-participants at comparable levels of risk for stress-related problems. Non-participants were women who reported high levels of stress (fairly often or very often stressed in the last month) but did not go on to participate in the digital coaching programme for stress management. Participants and non-participants were compared on stages of change to manage stress (Prochaska \& Velicer, 1997). Drawn from the transtheoretical model, the five stages of change-precontemplation, contemplation, preparation, action and maintenance-described the process of changing health-related behaviours.

For stress management, the precontemplation stage included individuals who neither intended to manage their stress nor planned on doing so in the next 6 months. Those in the contemplation stage were thinking about managing their stress in the next 6 months but had not made a commitment to take action. Individuals attempting to manage their stress in the last 30 days were in the preparation stage, whereas the action stage described those who were consistently managing their stress but had done so for less than 6 months. Finally, the maintenance stage characterized individuals who had actively managed their stress for at least 6 months (Prochaska \& Velicer, 1997). In addition to the stages of the change model, other measures of comparison included an adapted version of the PSS (Cohen et al., 1983), motivation to manage stress and confidence to manage stress.

\section{Statistical analyses}

Between-group comparisons (age groups) were made using chi-square tests for categorical data and one-way analysis of variance (ANOVA) for continuous variables. In light of the large sample size, we adopted a more conservative $p$-value of 0.001 for these analyses, so only those with a value lower than 0.001 were considered statistically significant. For variables with 
significant difference between age groups, post hoc pairwise comparisons (six pairs) were performed with Bonferroni adjustment for multiple comparisons. Each of the pairwise comparisons was tested at a significant level of $0.000167(0.001 / 6)$. All statistical analyses were done with SPSS for Windows, version 15.0 (SPSS Inc, Chicago, IL, USA).

\section{Results}

\section{Characteristics of stress programme participants}

The mean sample age for participants was 39.4 years [standard deviation $(\mathrm{SD})=10.4, N=63,690$ ]. white women were overly represented in the sample, and this representation increased with age $(68 \%$ to $82 \%$, $p<0.0001)$. The sample tended to be highly educated with $87.7 \%$ having a degree beyond a high school diploma $(p<0.001)$. Women aged 18 to 29 years were least likely to be employed, but the percent of women employed for other age groups was consistent $(18-29=86.7 \%$; $30-39=93.9 \% ; 40-49=95.2 \% ; 50-59=93.4 \%$, $p<0.0001)$.

\section{Stress level}

The PSS scores by age group are expressed as means \pm SDs in Table II. Younger women (18 to 29 years old) reported higher stress scores. For example, $71 \%$ of women aged 18 to 29 years reported feeling nervous, whereas only $55 \%$ of women aged 50 to 59 years felt the same. Younger women (18 to 29 years old) were also more likely to have difficulties pile up while under stress and feel angered that things were out of their control. Reports of lacking control appeared to gradually lessen with increased age. A higher percentage of older women (50 to 59 years old) reported feeling on top of things and that things were going their way.

Table II also shows that the seven items and total PSS score (calculated using the PSS-4) were significantly different between the four age groups as tested by one-way ANOVA $(p<0.0001)$. Post hoc analyses revealed a consistent pattern of similar differences between pairs of age groups (Table VI).

\section{Source of stress}

Table III summarizes women's self-reported source(s) of stress based on the SRRS (Holmes \& Rahe, 1967). Work was the primary source of stress for women of all ages but was proportionately higher in older women (50 to 59 years old). Older women (50 to 59 years old) were more likely to report health as a primary stress source than younger women (18 to 29 years old). Younger women (18 to 29 years old) were more likely to report personal and social life or school as their primary stressor compared with older women (50 to 59 years old). Financial stressors were common across the age groups but tended to decrease in older women ( 50 to 59 years old). Post hoc analyses between pairs of age groups revealed a consistent pattern of similar differences (Table VI).

Table II. Perceived stress scores by age stratification

\begin{tabular}{|c|c|c|c|c|c|c|c|c|c|c|}
\hline & \multirow{2}{*}{\multicolumn{2}{|c|}{$\frac{18-29 \text { years }}{(N=12,692)}$}} & \multirow{2}{*}{\multicolumn{2}{|c|}{$\frac{30-39 \text { years }}{(N=18,225)}$}} & \multirow{2}{*}{\multicolumn{2}{|c|}{$\frac{40-49 \text { years }}{(N=18,311)}$}} & \multirow{2}{*}{\multicolumn{2}{|c|}{$\frac{50-59 \text { years }}{(N=14,462)}$}} & \multirow{3}{*}{$\frac{\text { Effect sizes }}{(\text { Cohen's } d)}$} & \multirow{3}{*}{$\begin{array}{l}\text { Between } \\
\text { group }\end{array}$} \\
\hline & & & & & & & & & & \\
\hline & Mean & $\mathrm{SD}$ & Mean & $\mathrm{SD}$ & Mean & $\mathrm{SD}$ & Mean & $\mathrm{SD}$ & & \\
\hline $\begin{array}{l}\text { In the last month, how often have you felt that you } \\
\text { were unable to control the important things in your life? }\end{array}$ & 2.20 & 1.03 & 2.16 & 1.02 & 2.11 & 1.04 & 2.09 & 1.05 & 0.04 & $p<0.0001^{*}$ \\
\hline $\begin{array}{l}\text { In the last month, how often have you felt confident } \\
\text { about your ability to handle your personal problems? }\end{array}$ & 2.34 & 0.88 & 2.41 & 0.89 & 2.48 & 0.92 & 2.54 & 0.93 & 0.08 & $p<0.0001^{*}$ \\
\hline $\begin{array}{l}\text { In the last month, how often have you felt that things } \\
\text { were going your way? }\end{array}$ & 2.11 & 0.83 & 2.12 & 0.83 & 2.18 & 0.85 & 2.26 & 0.84 & 0.07 & $p<0.0001^{\star}$ \\
\hline $\begin{array}{l}\text { In the last month, how often have you felt difficulties were } \\
\text { piling up so high that you could not overcome them? }\end{array}$ & 2.21 & 1.11 & 2.16 & 1.09 & 2.04 & 1.10 & 1.92 & 1.10 & 0.10 & $p<0.0001^{*}$ \\
\hline $\begin{array}{l}\text { In the last month, how often have you felt nervous } \\
\text { and 'stressed'? }\end{array}$ & 3.02 & 0.91 & 2.88 & 0.92 & 2.74 & 0.95 & 2.66 & 0.96 & 0.14 & $p<0.0001^{*}$ \\
\hline $\begin{array}{l}\text { In the last month, how often have you been angered } \\
\text { because of things that were outside of your control? }\end{array}$ & 2.49 & 1.01 & 2.41 & 0.99 & 2.28 & 1.00 & 2.20 & 1.01 & 0.11 & $p<0.0001^{\star}$ \\
\hline $\begin{array}{l}\text { In the last month, how often have you felt you were } \\
\text { on top of things? }\end{array}$ & 2.09 & 0.84 & 2.07 & 0.84 & 2.14 & 0.87 & 2.20 & 0.86 & 0.06 & $p<0.0001^{\star}$ \\
\hline Total perceived stress score $(0-16)$ & 7.96 & 2.90 & 7.80 & 2.89 & 7.48 & 2.96 & 7.21 & 2.98 & 0.09 & $p<0.0001^{*}$ \\
\hline
\end{tabular}

Note. The first four items are the validated PSS-4 and were used to calculate the total PSS score. The higher the total PSS score, the higher the stress level.

* The seven items and the total PSS score were significantly different between four age groups, as tested by one-way analysis of variance (ANOVA), $p<0.0001$. 
Table III. Sources of stress

\begin{tabular}{|c|c|c|c|c|c|c|}
\hline & 18 to 29 years & 30 to 39 years & 40 to 49 years & 50 to 59 years & Effect size & \multirow{2}{*}{$\begin{array}{c}\text { Between } \\
\text { - group }\end{array}$} \\
\hline & \multicolumn{5}{|c|}{$(N=12,692 ; \%)(N=18,225 ; \%)(N=18,311 ; \%)(N=14,462 ; \%)($ Cohen's $w)$} & \\
\hline \multicolumn{7}{|l|}{ Primary stress source ${ }^{\dagger}$} \\
\hline Work & 28.1 & 31.5 & 34.8 & 38.8 & & $p<0.0001^{\star}$ \\
\hline School & 8.4 & 1.8 & 1.0 & 0.5 & & \\
\hline Money & 28.1 & 25.7 & 21.3 & 17.7 & & \\
\hline Home and family & 16.8 & 26.5 & 28.4 & 26.9 & & \\
\hline Personal and social life & 14.6 & 9.8 & 7.9 & 7.5 & & \\
\hline Health & 3.9 & 4.6 & 6.7 & 8.7 & 0.25 & \\
\hline \multicolumn{7}{|l|}{ Work stress } \\
\hline Too much work & 28.1 & 31.9 & 34.0 & 33.3 & 0.05 & $p<0.0001^{\star}$ \\
\hline Not enough control & 23.5 & 23.5 & 22.6 & 23.7 & 0.01 & $p=0.064$ \\
\hline Conflict with a coworker & 21.4 & 17.7 & 17.3 & 15.9 & 0.05 & $p<0.0001^{\star}$ \\
\hline Distractions & 38.0 & 31.0 & 26.6 & 24.7 & 0.10 & $p<0.0001^{\star}$ \\
\hline Change in work conditions & 39.9 & 35.3 & 33.1 & 31.5 & 0.06 & $p<0.0001^{\star}$ \\
\hline None of the above & 16.7 & 19.6 & 21.4 & 23.3 & 0.06 & $p<0.0001^{\star}$ \\
\hline \multicolumn{7}{|l|}{ Financial stress } \\
\hline Increase in income & 12.4 & 7.7 & 5.4 & 4.1 & 0.11 & $p<0.0001^{\star}$ \\
\hline Inadequate to meet basic expenses & 48.8 & 45.0 & 44.6 & 47.4 & 0.03 & $p<0.0001^{\star}$ \\
\hline Loss or damage to property & 7.1 & 6.7 & 6.6 & 5.9 & 0.02 & $p<0.0005^{\star}$ \\
\hline Paying bills & 41.8 & 38.7 & 31.0 & 22.9 & 0.15 & $p<0.0001^{\star}$ \\
\hline Decrease in income & 12.0 & 13.2 & 13.8 & 13.4 & 0.02 & $p<0.0001^{\star}$ \\
\hline Major purchase & 21.7 & 19.0 & 15.7 & 13.8 & 0.08 & $p<0.0001^{\star}$ \\
\hline None of the above & 9.7 & 11.9 & 16.0 & 18.8 & 0.10 & $p<0.0001^{*}$ \\
\hline \multicolumn{7}{|l|}{ Home and family stress } \\
\hline Ended relationship & 13.3 & 10.8 & 9.4 & 6.1 & 0.08 & $p<0.0001^{\star}$ \\
\hline Change in health of a loved one & 15.1 & 15.3 & 19.7 & 22.7 & 0.08 & $p<0.0001^{\star}$ \\
\hline Take care of others & 6.8 & 9.2 & 15.1 & 20.1 & 0.15 & $p<0.0001^{\star}$ \\
\hline Death of loved one & 14.2 & 13.6 & 14.8 & 16.2 & 0.03 & $p<0.0001^{\star}$ \\
\hline Change in residence & 41.9 & 22.3 & 13.3 & 9.9 & 0.28 & $p<0.0001^{\star}$ \\
\hline None of the above & 36.6 & 49.8 & 51.0 & 49.5 & 0.11 & $p<0.0001^{\star}$ \\
\hline \multicolumn{7}{|l|}{ Personal and social life stress } \\
\hline New relationship & 19.7 & 10.6 & 6.7 & 4.1 & 0.18 & $p<0.0001^{\star}$ \\
\hline Engaged or married & 15.8 & 7.7 & 3.4 & 1.9 & 0.20 & $p<0.0001^{*}$ \\
\hline Relationship problems & 42.1 & 37.9 & 32.0 & 25.3 & 0.13 & $p<0.0001^{\star}$ \\
\hline None of the above & 33.3 & 47.8 & 58.7 & 68.1 & 0.24 & $p<0.0001^{\star}$ \\
\hline \multicolumn{7}{|l|}{ Health stress } \\
\hline Frequent illness & 18.5 & 16.3 & 14.2 & 12.7 & 0.06 & $p<0.0001^{*}$ \\
\hline Recovered from illness or injury & 5.1 & 6.1 & 73. & 7.9 & 0.04 & $p<0.0001^{*}$ \\
\hline Diagnosed with illness or injury & 5.3 & 5.4 & 6.5 & 7.6 & 0.04 & $p<0.0001^{\star}$ \\
\hline None of the above & 71.9 & 73.2 & 73.3 & 73.5 & 0.01 & $p=0.011$ \\
\hline \multicolumn{7}{|l|}{ Situational stress ${ }^{\dagger}$} \\
\hline $\begin{array}{l}\text { Not enough time to spend with family because } \\
\text { of work or school }\end{array}$ & 19.6 & 20.2 & 18.2 & 15.5 & & $p<0.0001^{*}$ \\
\hline Family makes it hard to do well at work or school & 5.3 & 5.3 & 5.2 & 4.5 & & \\
\hline Work or school makes life hard & 30.3 & 21.0 & 19.3 & 18.7 & & \\
\hline Hard to meet all demands in life & 44.8 & 53.4 & 57.0 & 61.4 & 0.13 & \\
\hline
\end{tabular}

*All sources of stress items were significantly different between the four age groups, as tested by one-way analysis of variance (ANOVA), $p<0.0001$ except for Not enough control.

${ }^{\dagger}$ Forced choice item.

All sources of work stress were significantly different between the four age groups, as tested by chi-square test $(p<0.0001)$, except for the not enough control item. Younger women (aged 18 to 29 years) were also more likely to be stressed by conflict with coworkers and changes in their work conditions. With only a few exceptions, post hoc analyses between pairs of age groups revealed a similar pattern of differences (Table VI). For home and family stress, younger women (18 to 29 years old) were more likely to report 
ending a relationship or a change in residence as major stressors. Older women (50 to 59 years old) were three times more likely than their younger counterparts to report stress in response to taking care of others. All sources of home and family stress were significantly different between the four age groups, as tested by chisquare tests $(p<0.0001)$. With only a few exceptions, post hoc analyses between pairs of age groups revealed similar trends (Table VI).

With respect to situational stressors, older women (aged 50 to 59 years) tended to struggle with too many demands and not enough time to meet them. All pairs were statistically significant for situational stressors $(p<0.0001)$.

\section{Stress symptoms}

Table IV presents the reported symptoms. There were significant differences among the four age groups on the prevalence of stress symptoms, except for fatigue, as tested by the chi-square test $(p<0.0001)$. Post hoc analyses between pairs of age groups revealed similar trends across all categories of symptoms, with somewhat fewer significant differences observed between the youngest (18-29 versus 30-39) and the oldest (40-49 versus 50-59) pairs of participants (Table VI).

\section{Physical symptoms}

Women aged 18 to 39 years were most likely to experience headache as their most prevalent physical symptom associated with stress $(73.4 \%, p<0.0001)$. Although headache prevalence declined sharply for women over 40 years old, it still occurred in more than half of the women aged 50 to 59 years $(51.5 \%$, $p<0.0001)$. Fatigue was also very common and consistent across age groups. Gastrointestinal problems and backache decreased with age. Not surprisingly, chronic pain increased with age.

\section{Psychological symptoms}

Younger women (18 to 29 years old) were most likely to report negative emotional reactions to stress. Worry/anxiety was the most commonly reported emotional symptom in the youngest group (76.0\%, $p<0.0001)$ compared with the older groups. Anger and irritability were most frequently reported in middle-aged women (aged 30 to 39 years) $(72.3 \%$, $p<0.0001)$.

\section{Behavioural and emotional symptoms}

Lack of interest $(62.6 \%, p<0.0001)$, loss of appetite $(27.0 \%, p<0.001)$ and sleep disturbance (59.9\%, $p<0.001)$ were the most common behavioural and emotional symptoms among 18 to 29 year olds, and prevalence rates differed significantly from their older groups. For women aged 30 years and above, sleep problems were the most common behavioural symptom and increased with age, rising from $62 \%$ for the 30 - to 39 -year-olds to $65.1 \%$ for the 40 - to 49 -year-olds and $68 \%$ for women aged 50 to 59 years old.

Table IV. Common symptoms of stress by age

\begin{tabular}{|c|c|c|c|c|c|c|}
\hline & 18 to 29 years & 30 to 39 years & 40 to 49 years & 50 to 59 years & Effect size & \multirow{2}{*}{$\begin{array}{c}\text { Between } \\
\text { group }\end{array}$} \\
\hline & $(N=12,692 ; \%)$ & $(N=18,225 ; \%)$ & $(N=18,311 ; \%)$ & $(N=14,462 ; \%)$ & (Cohen's $w$ ) & \\
\hline \multicolumn{7}{|l|}{ Physical symptoms } \\
\hline Headache & 73.4 & 70.0 & 62.5 & 51.5 & 0.17 & $p<0.0001^{*}$ \\
\hline Backache & 38.9 & 34.6 & 31.3 & 29.4 & 0.07 & $p<0.0001^{*}$ \\
\hline Chronic pain (other than headache or backache) & 9.3 & 10.7 & 12.9 & 14.8 & 0.06 & $p<0.0001^{*}$ \\
\hline Fatigue & 64.2 & 64.6 & 64.4 & 64.1 & 0.004 & $p=0.823$ \\
\hline Gastrointestinal problems & 57.6 & 51.3 & 46.8 & 42.6 & 0.10 & $p<0.0001^{*}$ \\
\hline None of the above & 5.0 & 5.8 & 7.8 & 9.4 & 0.06 & $p<0.0001^{*}$ \\
\hline \multicolumn{7}{|l|}{ Psychological symptoms } \\
\hline Cannot concentrate & 58.6 & 54.2 & 52.6 & 52.3 & 0.05 & $p<0.0001^{*}$ \\
\hline Worry or anxiety & 76.0 & 68.7 & 64.1 & 62.5 & 0.10 & $p<0.0001^{*}$ \\
\hline Low mood & 63.0 & 56.8 & 54.0 & 52.4 & 0.08 & $p<0.0001^{*}$ \\
\hline Anger or irritability & 74.0 & 72.3 & 62.2 & 51.6 & 0.18 & $p<0.0001^{*}$ \\
\hline None of the above & 2.6 & 3.3 & 4.6 & 5.9 & 0.06 & $p<0.0001^{*}$ \\
\hline \multicolumn{7}{|l|}{ Emotional and behavioural symptoms } \\
\hline Difficulty sleeping & 59.9 & 62.4 & 65.1 & 67.8 & 0.06 & $p<0.0001^{*}$ \\
\hline Eat more & 47.1 & 47.9 & 48.8 & 51.1 & 0.03 & $p<0.0001^{*}$ \\
\hline Eat less & 27.0 & 21.2 & 17.5 & 14.0 & 0.11 & $p<0.0001^{*}$ \\
\hline Lack of interest & 62.6 & 58.6 & 54.8 & 52.4 & 0.07 & $p<0.0001^{*}$ \\
\hline None of the above & 6.0 & 6.1 & 6.0 & 5.9 & 0.003 & $p=0.928$ \\
\hline
\end{tabular}

${ }^{\star}$ All the items for stress symptoms between the four age groups were significant, except for fatigue and none of the above for the four emotional and behavioural symptoms, as tested by the chi-square test, $p<0.0001$. 


\section{Coping strategies}

Older adults (50 to 59 years old) reported at baseline that they were more confident in their ability to handle personal problems, with half of them stating they were fairly or very confident about managing stress. Only $40 \%$ of younger women (18 to 29 years old) felt similarly confident.

Table V presents the most commonly used methods for coping with stress by age group. Coping strategies showed marked differences across age groups. One striking finding is that younger women (18 to 29 years old) were more likely to use unhealthy coping strategies such as sleeping more, drinking more alcohol, smoking and/or becoming irritable in response to stress.

Women aged 30 to 39 years were more likely to report working harder and faster, while withdrawing emotionally. On the other hand, older women (50 to 59 years old) learned to plan for and use healthier stress management techniques. For example, older women (50 to 59 years old) were more likely to feel they were better at recognizing and preparing for stressful situations. Older women (50 to 59 years old) were also more likely to make time for relaxation and practise specific stress management techniques. They tended to pray or meditate more, remain active and confront sources of stress more frequently than their younger counterparts.

Women were asked about the social support available to them as well as their comfort level in asking for help. The youngest group (18 to 29 years old) was more likely to seek out friends and ask for help coping with stress than older women (Table V). Only $56 \%$ of the sample reported having enough support $(p<0.0001)$. Although most women $(70 \%)$ had a close confidante available for personal matters $(p<0.0001)$, women reported being uncomfortable asking for help, with $62 \%$ to $65 \%$ by age group indicating they were uncomfortable imposing on others $(p<0.0001)$. Post hoc analyses generally showed significant differences between pairs of age groups with a small number of exceptions (Table VI).

\section{Non-participants comparison}

The non-participant sample's average age was 39.7 years $(\mathrm{SD}=10.5, N=165,442)$, and white women were overly represented in the sample. Most $(85.5 \%)$ went beyond high school, and most worked outside the home $(71.8 \%)$. Although the percentages of demographic characteristics (age, race, education and employment status) were similar for both the partici-

Table V. Coping strategies for stress management

\begin{tabular}{|c|c|c|c|c|c|c|}
\hline & 18 to 29 years & 30 to 39 years & 40 to 49 years & 50 to 59 years & Effect size & Between \\
\hline & $(N=12,692 ; \%)$ & $(N=18,225 ; \%)$ & $(N=18,311 ; \%)$ & $(N=14,462 ; \%)$ & (Cohen's w) & \\
\hline \multicolumn{7}{|l|}{ Prevention techniques } \\
\hline Balance & 34.0 & 31.3 & 34.3 & 33.5 & 0.03 & $p<0.0001^{*}$ \\
\hline Prepared & 23.7 & 25.2 & 28.1 & 29.3 & 0.05 & $p<0.0001^{\star}$ \\
\hline Planned relaxation & 11.7 & 12.1 & 17.8 & 22.7 & 0.12 & $p<0.0001^{*}$ \\
\hline Stress management techniques & 13.7 & 14.4 & 17.3 & 21.8 & 0.08 & $p<0.0001^{\star}$ \\
\hline Manage time effectively & 29.4 & 27.5 & 30.2 & 30.0 & 0.02 & $p<0.0001^{*}$ \\
\hline Enjoyable activities & 31.8 & 25.0 & 26.6 & 30.2 & 0.06 & $p<0.0001^{*}$ \\
\hline None of the above & 29.8 & 33.4 & 30.2 & 27.6 & 0.05 & $p<0.0001^{\star}$ \\
\hline \multicolumn{7}{|l|}{ Coping techniques } \\
\hline Sleep more & 38.5 & 30.1 & 27.0 & 24.1 & 0.11 & $p<0.0001^{\star}$ \\
\hline Drink more caffeine & 36.0 & 35.0 & 30.5 & 26.2 & 0.08 & $p<0.0001^{\star}$ \\
\hline Seek out friends for support & 43.6 & 37.1 & 33.7 & 33.1 & 0.08 & $p<0.0001^{*}$ \\
\hline Smoke cigarette & 13.9 & 10.5 & 9.6 & 7.2 & 0.07 & $p<0.0001^{*}$ \\
\hline Ask for help & 11.6 & 9.7 & 9.6 & 10.2 & 0.03 & $p<0.0001^{\star}$ \\
\hline Distract myself & 53.6 & 44.5 & 41.9 & 47.6 & 0.08 & $p<0.0001^{\star}$ \\
\hline Pray or meditate & 23.0 & 26.6 & 34.2 & 38.9 & 0.13 & $p<0.0001^{*}$ \\
\hline Drink alcohol & 17.5 & 13.3 & 12.4 & 9.3 & 0.08 & $p<0.0001^{\star}$ \\
\hline Physical activity & 20.6 & 18.2 & 21.6 & 24.4 & 0.05 & $p<0.0001^{\star}$ \\
\hline Get irritable & 64.9 & 61.3 & 48.9 & 36.2 & 0.22 & $p<0.0001^{*}$ \\
\hline Relax, breathe and unwind & 18.1 & 17.1 & 20.1 & 23.4 & 0.06 & $p<0.0001^{\star}$ \\
\hline Confront stress and work to change & 16.6 & 17.3 & 18.7 & 20.8 & 0.04 & $p<0.0001^{\star}$ \\
\hline Ignore needs and work harder and faster & 38.6 & 41.4 & 39.7 & 38.1 & 0.03 & $p<0.0001^{\star}$ \\
\hline Shopping & 38.2 & 30.8 & 26.3 & 25.2 & 0.10 & $p<0.0001^{\star}$ \\
\hline Keep a journal & 9.2 & 6.2 & 5.7 & 6.0 & 0.05 & $p<0.0001^{\star}$ \\
\hline Withdraw emotionally & 43.8 & 44.0 & 41.3 & 41.6 & 0.03 & $p<0.0001^{\star}$ \\
\hline
\end{tabular}

${ }^{\star}$ All the items for prevention and coping techniques between the four age groups were significant, as tested by the chi-square test, $p<0.0001$. 
Table VI. Post hoc analysis

18-29 versus $18-29$ versus $18-29$ versus $30-39$ versus $30-39$ versus $40-49$ versus 30-39 years $40-49$ years $50-59$ years $40-49$ years $50-59$ years $50-59$ years

Perceived stress score

In the last month, how often have you felt that you were unable to control the important things in your life?

In the last month, how often have you felt confident about your ability to handle your personal problems?

In the last month, how often have you felt that things were going your way?

In the last month, how often have you felt difficulties were piling up so high that you could not overcome them?

In the last month, how often have you felt nervous and 'stressed?'

In the last month, how often have you been angered because of things that were outside of your control? In the last month, how often have you felt you were on top of things?

Total perceived stress score $(0-16)$

Work stress

Too much work

Not enough control

Conflict with a coworker

Distractions

Change in work conditions

None of the above

Home and family stress

Ended relationship

Change in health of a loved one

Take care of others

Death of loved one

Change in residence

None of the above

Financial stress

Increase in income

Income adequate to meet basic expenses

Loss or damage to property

Paying bills

Decrease in income

Major purchase

None of the above

Personal and social life stress

New relationship

Engaged or married

Relationship problems

None of the above

Health stress

Frequent illness

Recovered from illness or injury

Diagnosed with illness or injury

None of the above

Primary stress source

Work

School

Money

Home and Family

Personal and social life

Health 
Table VI. Continued

\begin{tabular}{|c|c|c|c|c|c|c|}
\hline & $\begin{array}{l}18-29 \text { versus } \\
30-39 \text { years }\end{array}$ & $\begin{array}{c}18-29 \text { versus } \\
40-49 \text { years }\end{array}$ & $\begin{array}{l}18-29 \text { versus } \\
50-59 \text { years }\end{array}$ & $\begin{array}{c}30-39 \text { versus } \\
40-49 \text { years }\end{array}$ & $\begin{array}{c}30-39 \text { versus } \\
50-59 \text { years }\end{array}$ & $\begin{array}{l}40-49 \text { versus } \\
50-59 \text { years }\end{array}$ \\
\hline \multicolumn{7}{|l|}{ Situational stress } \\
\hline $\begin{array}{l}\text { Not enough time to spend with family because of } \\
\text { work or school }\end{array}$ & * & * & * & * & * & * \\
\hline \multicolumn{7}{|l|}{ Family makes it hard to do well at work or school } \\
\hline \multicolumn{7}{|l|}{ Work or school makes life hard } \\
\hline \multicolumn{7}{|l|}{ Hard to meet all demands in life } \\
\hline Physical symptoms & * & * & * & * & * & * \\
\hline Headache & * & * & * & * & * & \\
\hline Backache & * & * & * & * & * & * \\
\hline \multicolumn{7}{|l|}{ Chronic pain (other than headache or backache) } \\
\hline Fatigue & * & * & * & * & * & * \\
\hline Gastrointestinal problems & & * & * & * & * & * \\
\hline Psychological symptoms & * & * & * & & & \\
\hline Cannot concentrate & * & * & * & * & * & \\
\hline Worry or anxiety & * & * & * & * & * & \\
\hline Low mood & & * & * & * & * & * \\
\hline Anger or irritability & * & * & * & * & * & * \\
\hline None of the above & * & * & * & & & \\
\hline \multicolumn{7}{|l|}{ Emotional and behavioural symptoms } \\
\hline Difficulty sleeping & * & * & * & * & * & * \\
\hline Eat more & & & * & & * & * \\
\hline Eat less & * & * & * & * & * & * \\
\hline Lack of interest & * & * & * & * & * & * \\
\hline None of the above & * & * & * & * & * & * \\
\hline \multicolumn{7}{|l|}{ Prevention techniques } \\
\hline \multicolumn{7}{|l|}{ Balance } \\
\hline Prepared & * & & & * & * & \\
\hline Planned relaxation & & * & * & * & * & \\
\hline Stress management techniques & & * & * & * & * & * \\
\hline Manage time effectively & & * & * & * & * & * \\
\hline Enjoyable activities & & & & * & * & \\
\hline None of the above & * & * & & & * & * \\
\hline \multicolumn{7}{|l|}{ Coping techniques } \\
\hline Sleep more & * & * & * & * & * & * \\
\hline Drink more caffeine & & * & * & * & * & * \\
\hline Seek out friends for support & * & * & * & * & * & \\
\hline Smoke cigarette & * & * & * & & * & * \\
\hline Ask for help & * & * & & & & \\
\hline Distract myself & * & * & * & * & * & * \\
\hline Pray or meditate & * & * & * & * & * & * \\
\hline Drink alcohol & * & * & * & & * & * \\
\hline Physical activity & * & & * & * & * & * \\
\hline Get irritable & * & * & * & * & * & * \\
\hline Relax, breathe and unwind & & * & * & * & * & * \\
\hline Confront stress and work to change & & * & * & & * & * \\
\hline Ignore needs and work harder and faster & * & & & & * & \\
\hline Shopping & * & * & * & * & * & \\
\hline Keep a journal & * & * & * & & & \\
\hline Withdraw emotionally & & * & & * & * & \\
\hline
\end{tabular}

${ }^{\star}$ Each of the pairwise comparisons was significant at 0.000167 (0.001/6).

pants and the non-participants, the differences between the two groups were statistically significant $(p<0.0001)$.
Participants had a lower stress behaviour score as measured by the PSS $(p<0.0001)$ and a higher motivation to manage stress $(p<0.0001)$ compared 
with non-participants. When examining the stages of change model for stress management, the participants were more likely to be in the contemplation stage (35.8\% versus $32.5 \%, p<0.0001)$ or the preparation stage $(27.3 \%$ versus $24.2 \%, p<0.0001)$ compared with non-participants, who were more likely to be in the maintenance stage of stress management $(26.3 \%$ versus $22.2 \%, p<0.0001)$. The participants and the nonparticipants did not differ statistically on confidence to manage stress.

\section{Discussion}

Prior research has established that women are more likely to exhibit higher levels of stress and stress symptoms when compared with men (APA, 2009; Matud, 2004), yet there is a paucity of research on women's unique stress characteristics and help-seeking behaviour for stress management. In this study, we specifically looked at a large sample of women participating in a digital health coaching programme for stress management. The sample of women evaluated here allowed us to examine how stress characteristics varied within specific age groups.

Although this is admittedly a cross-sectional data sample, the findings on sources of stress fit a developmental model (Table III). Younger women (18 to 29 years old) had more concerns regarding life transitions like graduation, a new job, dynamic relationship status and changes in residence. Concerns with money were also more prevalent in the younger groups. Older women (50 to 59 years old) reported greater concerns for their health, the health of loved ones and their role as caretakers. Women of all ages consistently identified work as a source of stress and reported experiencing time pressures (Table III). Work stress was proportionately higher in older women (aged 50 to 59 years).

Over half of the participants reported experiencing symptoms in response to stress (Table IV). Younger women (aged 18 to 29 years) were most likely to report negative emotional reactions to stress, which is consistent with developmental patterns in the stress literature (Neupert et al., 2007). However, unlike previous stress research, anger and irritability were most frequently reported in women aged 30 to 39 years and not in the youngest age group, within which worry and anxiety were the most commonly reported psychological symptom.

Although the perception of lacking control appeared relatively consistent across age groups, older women (50 to 59 years old) were more confident and comfortable regarding their ability to cope with stress (Table V). They also used healthier coping strategies relative to their younger counterparts. More specifically, the older group of women appeared to have adopted a more proactive, meditative and accepting approach to coping. This provides tentative support for the notion that age and experience lead to a greater level of self-efficacy and a healthier approach to dealing with stress. However, it does not rule out the possibility that younger women may benefit from more exposure to these stress prevention strategies being used more frequently by their older counterparts. One of the potential benefits of deploying scalable interventions such as digital health coaching to large populations is the opportunity to help young women build the skills necessary to manage and prevent stress earlier in life, instead of acquiring the skills over decades of trial and error.

The participants and the non-participants did not differ significantly on confidence to manage stress, but the participants were more motivated to manage their stress. The participants and the non-participants were at different stages of change for managing stress. The participants were in the contemplation or preparation stage, which fits the transtheoretical model given their level of commitment to managing stress. The nonparticipants, who were more likely to be in the maintenance stage, may have perceived that they are handling their stress and therefore did not believe they needed to participate in the digital health coaching programme despite their high-risk status.

Women are clearly interested in assistance with stress management, as evidenced by the high number of participants in the digital health coaching programme. Technology-based stress management programmes are an increasingly attractive option, since they are highly scalable and can be disseminated to unlimited numbers of participants at low cost. A number of such programmes have been developed in recent years, showing promising results both in terms of symptomatic improvements and user satisfaction (Hasson, Anderberg, Theorell, \& Arnetz, 2005; van Straten, Cuijpers, \& Smits, 2008). Increasingly, health insurance plans or employers offer their members/employees access to digital health coaching to promote good health, prevent disease and provide stress management tools (Bedrosian, Striegel-Moore, Wang, \& Schwartz, 2010; Naydeck, Pearson, Ozminkowski, Day, \& Goetzel, 2008; Schwartz et al., 2011).

Although social support has been found to mitigate the impact of stress (Cohen \& Wills, 1985), many women reported being dissatisfied with their social support available. Even though most women (70\%) had a close confidante, women of all ages reported being uncomfortable asking for help. Feeling uncomfortable imposing on others was also universal. These results suggest that the use of social support is by no means given among women, and further, there is a stark difference between access to social support and actual utilization of such resources. The findings suggest that technology-based, confidential solutions like digital health coaching may reach women who may not otherwise seek or receive help for stress management. 


\section{Limitations}

The study utilized a real world population without control over incentives offered for participating in the digital health coaching programme (only 35\% of people self-reporting they were experiencing high stress went on to participate in the digital health coaching programme for stress management). Additionally, the sample was predominately white, highly educated and computer literate with Internet access, thereby limiting the generalizability of findings to other demographics. Computer literacy and Internet access are essential elements of this delivery modality that mitigates these two limitations to some degree.

As stated previously, developmental interpretations of age group differences should be viewed with some caution since age differences could simply reflect differences between the specific cohorts utilized in this study. Because of the study's large sample size, the effect sizes are small, indicating that the study was statistically overpowered. However, it can be argued that even small differences between age groups point to the importance of tailoring interventions to reflect demographic, psychological and symptomatic differences between individuals. Although speculations on clinical significance are beyond the scope of the present study, the authors hope it will provide descriptive benchmarks for others to evaluate the clinical implications in future research.

\section{Implications for stress management interventions}

The limitations noted above may restrict the ability to generalize to groups of women with other demographics or women not seeking assistance for stress management. However, this does not undermine the descriptive value of these data in understanding the nature of stress within this group of women and other women like them. Further, given the size of the database and the detail within the data constructs, these descriptive data groups can serve as a benchmark from which other data on women (including demographically different samples) and men experiencing stress can be compared. Moreover, the observed patterns of symptoms and coping strategies among women of different ages can be used to inform development of remediation techniques in the future, particularly if such interventions can be tailored to reflect multiple aspects of the individual's stress experience.
More research is needed to identify the features and delivery modes of tailored online stress management solutions that might be most attractive to and beneficial for women. Nonetheless, the data from our sample can be used to inform programme design in order to increase participation and efficacy based on age group considerations and unique sources of stress. The differences in emotional reactions, symptoms, sources of stress and preferred coping strategies between current generations of women all speak to the importance of avoiding a 'one size fits all' approach when designing stress management programmes in favour of providing highly tailored interventions based on algorithms, which take all these variables into account. The fact that women of all ages in our sample were hesitant to ask for social support suggests that private, confidential online stress management programmes could be an effective first step, especially if designed to assess and address barriers that inhibit participants from seeking help from other sources.

Given that women are beset with multiple role responsibilities and extensive time demands, it is important for them to be able to access stress management programmes at their convenience. Over half of women (57\%) with home access go online on a typical day, and $66 \%$ of women with Internet access at work are online daily (Fallows, 2005). Because of the convenience and scalability of the Internet as a programme delivery method, online stress management programmes like digital health coaching may be a readily accessible solution for this target population. Emerging mobile communications technologies will confer many of the same advantages.

The fact that 63,690 women participated in the digital coaching programme speaks to its potential role in ameliorating the harmful effects of stress in the population. Although initial outcome data suggest that participants in the programme did benefit significantly from it (Wiegand et al., 2010), controlled studies with more effective follow-up are necessary in order to determine the effectiveness of digital coaching for stress management. However, given that unlimited numbers of individuals could use these interventions, even very modest positive results could make a significant difference in the quality of life across a large population.

\section{REFERENCES}

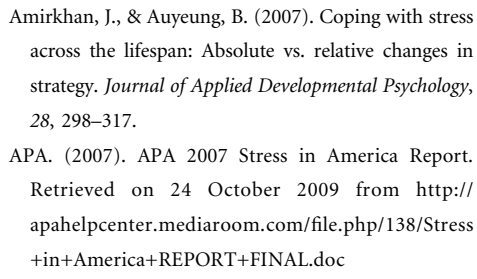

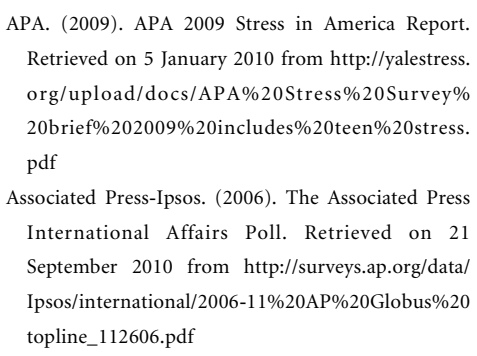

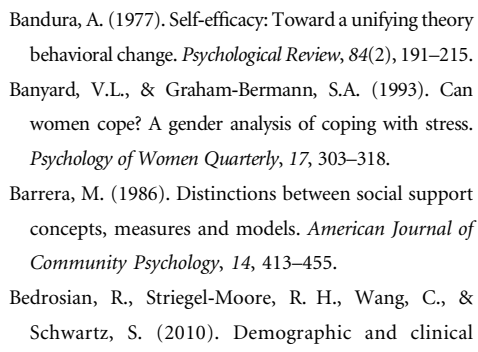


characteristics of individuals utilizing an Internet-based digital coaching program for recovering from binge eating. International Journal of Eating Disorders. doi:10.1002/eat.20844

Cohen, S., Gottlieb, B.H., \& Underwood, L.G. (2000). Social relationships and health. In S. Cohen, L.G. Underwood, \& B.H. Gottlieb (Eds.), Social support measurement and intervention: A guide for health and social scientists (pp. 1-25). New York, NY: Oxford University Press.

Cohen, S., Kamarck, T., \& Mermelstein, R. (1983). A global measure of perceived stress. Journal of Health and Social Behavior, 24, 385-396.

Cohen, S., \& Wills, T.A. (1985). Stress, social support and the buffering hypothesis. Psychological Bulletin, 98(2), 310-357.

Compas, B.E. (1998). An agenda for coping research and theory: Basic and applied developmental issues. International Journal of Behavioral Development, 22 (2), 231-237.

Crisp, D.A. \& Rickwood, D. (2006). Reducing stigma and improving mental health literacy through schoolbased mental illness education. Australian Psychological Society, 75-79.

Davis, M., Eshelman, E.R., \& McKay, M. (2000). The relaxation \& stress reduction workbook (5th edn). Oakland, CA: New Harbinger Publications.

Donald, M., Dower, J., Lucke, J., \& Rachael, B. (2000). The Queensland Young Peoples' Mental Health Survey report. Brisbane, Queensland, Australia: Public Health Services, Queensland Health.

Fallows, D. (2005). How women and men use the Internet. PEW Internet o American Life Project. Retrieved on 6 January 2010 from http://www. pewtrusts.org/uploadedFiles/wwwpewtrustsorg/ Reports/Society_and_the_Internet/PIP_Women_ Men_122805.pdf

Foundation for Integrated Research in Mental Health. (2007). Test 4 Mental Health Survey. Retrieved on 6 January 2010 from http://www.firmindia.net/news. php?SCRCAT $=1 \&$ ITMTYP=Views\&ITMID $=84$

Hamer, M., Molloy, G.J., \& Stamatakis, E. (2008). Psychological distress as a risk factor for cardiovascular events: Pathophysiological and behavioral mechanisms. Journal of the American College of Cardiology, 52, 2156-2162.

Hasson, D., Anderberg, U.M., Theorell, T., \& Arnetz, B.B. (2005). Psychophysiological effects of a web-based stress management system: A prospective, randomized controlled intervention study of IT and media workers. BMC Public Health, 25(5), 78.

Holmes, T.H., \& Rahe, R.H. (1967). The Social Readjustment Rating Scale. Journal of Psychometrical Research, 11(2), 213-218.

Jacobs, R., Pawlak, C.R., Mikeska, E., Meyer-Olson, D., Martin, M., Heijnen, C.J., ... Schmidt, R.E. (2001). System lupus erythematosus and rheumatoid arthritis patients differ from healthy controls in their cytokine pattern after stress exposure. Rheumatology, 40(8), 868-875.

Kayser, K., Sormanti, M., \& Strainchamps, E. (1999). Women coping with cancer. The influence of the relationship factors on psychosocial adjustment. Psychology of Women Quarterly, 23, 725-739.

Kessler, R.C., \& McLeod, J.D. (1984). Stress differences in vulnerability to undesirable life events. American Sociological Review, 49, 620-631.

Kessler, R. C., Berglund, P.A., Bruce, M.L., Koch, J.R., Laska, E.M., Leaf, P.J., ... Wang, P.S. (2001). The prevalence and correlates of untreated serious mental illness. Health Services Research, 36(6), 987-1007.

Komaroff, A.L., Masuda, M., \& Holmes, H. (1968). The Social Readjustment Rating Scale: A comparative study of Negro, Mexican and white Americans. Journal of Psychosomatic Research, 12(2), 121-128.

Laitinen, J., Ek, E., \& Sovio, U. (2002). Stress-related eating and drinking behavior and body mass index and predictors of this behavior. Preventive Medicine, 34(1), 29-39.

Lee, C. (2001). Experiences of family caregiving among older Australian women. Journal of Health Psychology, 6, 393-404.

Locke, R.G., Weaver, A.L., Melton, L.J., \& Talley, N.J. (2004). Psychosocial factors are linked to gastrointestinal disorders: A population based nested casecontrol study. The American Journal of Gastroenterology, 99(2), 350-357.

Martin, PR., Lae, L., \& Reece, J. (2007). Stress as a trigger for headaches: Relationship between exposure and sensitivity. Anxiety, Stress \& Coping, 20(4), 393-407.

Mathews, N.T., Stubits, E., \& Nigam, M.P. (1982). Transformations of episodic migraine into daily headache: Analysis of factors. Headache: The Journal of Head and Face Pain, 22(2), 66-68.

Matud, M.P. (2004). Gender differences in stress and coping styles. Personality and Individual Differences, 37, 1401-1415.

Naydeck, B.L., Pearson, J.A., Ozminkowski, R.J., Day, B.T., \& Goetzel, R.Z. (2008). The impact of the highmark employee wellness programs on 4-year healthcare costs. Journal of Occupational Environmental Medicine, 50(2), 146-156.

Neupert, S.D., Almeida, D.M., \& Charles, S.T. (2007). Age differences in reactivity to daily stressors: The role of personal control. The Journals of Gerontology Series B: Psychological Sciences and Social Sciences, 62, 216-225.

Oliver, M.I., Pearson, N., Coe, N., \& Gunnell, D. (2005). Help-seeking behavior in men and women with common mental health problems: Cross-sectional study. British Journal of Psychiatry, 186, 297-301.

Oman, R.F., \& King, A.C. (2000). The effect of life events and exercise program format on the adoption and maintenance of exercise behavior. Health Psychology, 2000, 605-612.

Ozbay, F., Fitterling, H., Charney, D., \& Southwick, S. (2008). Social support and resilience to stress across the life span: A neurobiologic framework. Current Psychiatry Reports, 10, 304-310.

Parrott, A.C. (1995). Stress modulation over the day in cigarette smokers. Addiction, 90, 233-244.

Pohorecky, L.A. (1991). Stress and alcohol interaction: An update of human research. Alcoholism: Clinical and Experimental Research, 15(3), 438-459.
Priftis, K.N., \& Anthracopoulos, M. B. (2008). The causal relationship between stress and asthma. Allergologia et Immunopathologia, 36, 343-346.

Prochaska, J.O., \& Velicer, W.F. (1997). The transtheoretical model of health behavior change. American Journal of Health Promotion, 12, 38-48.

Ptacek, J.T., Smith, R.E., \& Zanas, J. (1992). Gender, appraisal, and coping: A longitudinal analysis. Journal of Personality, 60, 747-770.

Rahe, R.H., \& Tolles, R.L. (2002). The Brief Stress and Coping Inventory: Psychometric properties. International Journal of Stress Management, 9, 61-70.

Rosario, M., Shinn, M., Morch, H., \& Huckabee, C.B. (1988). Gender differences in coping and social supports: Testing socialization and role constraint theories. Journal of Community Psychology, 16, 55-69. Schwartz, S.M., Day, B., Wildenhaus, K., Silberman, A., Wang, C. \& Silberman, J. (2011). The impact of an online disease management program on medical costs among health plan members. American Journal of Health Promotion, 25(2), 126-133.

Selye, H. (1976). The stress of life. New York: McGraw-Hill. Shiloah, E., \& Rapoport, M.J. (2006). Psychological stress and new onset diabetes. Pediatric Endocrinology Reviews, 3(3), 272-275.

Smith, A. (2002). Effects of caffeine on human behavior. Food and Chemical Toxicology, 40(9), 1243-1255.

Steptoe, A., Lipsey, Z., \& Wardle, J. (1998). Stress, hassles and variations in alcohol consumption, food choice and physical exercise: A diary study. British Journal of Health Psychology, 3, 51-63.

Stone, A.A., Schwartz, J.E., Broderick, J.E., \& Deaton, A. (2010). A snapshot of the age distribution of psychological well-being in the United States. Proceedings of the National Academy of Sciences, 107(22), 9985-9990.

van Straten, A., Cuijpers, P., \& Smits, N. (2008). Effectiveness of a web-based self-help intervention for symptoms of depression, anxiety, and stress: Randomized controlled trial. Journal of Medical Internet Research, 10(1), e7.

Strecher, V.J. (2009). eHealth for health related behavior change and disease management. Presented at the eHealth Forum 2009. Hong Kong Academy of Medicine. Retrieved on 8 January 2010 from http:// www.ehealthforum2009.org/lang/en-us/about/ keynote-speakers/strecher/

Thadani, P.V. (2002). The intersection of stress, drug abuse and development. Psychoneuroendocrinology, 27, 221-230.

Wetherington, E., \& Kessler, R.C. (1986). Perceived support, received support, and adjustment to stressful life events. Journal of Health and Social Behavior, 27, 78-89.

Wiegand, B., Luedtke, K., Mona Nair, D.F., Aleles, M., \& McCloskey, R. (2010). Efficacy of a comprehensive program for reducing stress in women: A prospective, randomized trial. Current Medical Research \& Opinion, 26(4), 991-1002.

Woon, T.H., Masuda, M., Wagner, N.N., \& Holmes, T.H. (1971). The Social Readjustment Rating Scale: A cross-cultural study of Malaysians and Americans. Journal of Cross-Cultural Psychology, 2(4), 373-386. 